\title{
EL VENERABLE ARNALDO AMALARICO (h. 1196-1225): IDEA Y REALIDAD DE UN CISTERCIENSE ENTRE DOS CRUZADAS!
}

\author{
POR
}

\author{
Martín Alviria Cabrer
}

Universidad Compiutense de Madrid

\begin{abstract}
Resumen
Tras ser elegido por méritos propios abad general de la poderosa Orden dei Cister, el catalán Arnaldo Amalarico ( $\uparrow$ 1225) dirigió como legado papal la lucha pacífica y luego violenta de la Iglesia contra el catarismo occitano. Su liderazgo no sólo marcó los primeros destinos de la Cruzada Albigense (1208-1214) sino que también tưo reflejo durante la Cruzada de Las Navas de Tolosa (1212), a la que se unió tras ser elegido arzobispo de Narbona. Mientras, en ambas empresas, el venerable Arnaldo mostró lo mejor de sus cualidades he hombre de acción, en la primera encarnó lo peor de la violencia y el fanatismo que detinieron la guerra santa contra los señores occitanos acusados de herejía. Decidida esta cruzada en la batalla de Muret (1213), Arnaldo perdió su antcrior protagonismo, desprestigiándose en una pugna feudal por el ducado dc Narbona debida a ambiciones señoriales y, quizá, familiares. Personalidad excepcional, el cisterciense Arnaldo Amalarico es, sin duda, uno de Ios principales protagonistas del Occidente medieval de principios del siglo XIII.
\end{abstract}

\section{ABSTRACT}

Venerable Arnaldo Amalarico (h. 1196-1225)

After being elected as primal abbot of the powerful Cislercien Order, the Catalan Arnofo Amalric ( +1225$)$ led as papal legate the pacific and then violent

Este trabajo y otros citados de mi autoría forman parte del proyecto de investigación de la DGICYT situlado "La gueria en la Edad Media Hispánica: implicaciones materiales y mentales" $\left(\mathbb{N}^{\circ}\right.$ PB93-0018) bajo la dirección de D. Emilio Mitre Fernández, Catedrático de Historia Medieval de la Universidad Complutense de Madrid. 


\begin{abstract}
Church fight against the Occitan catharism. His leadership marked not only the early destinies of the Albigensian Crusade (1208-1214) and it had some influence on the Crusade of Las Navas de Tolosa (1212), to which he was joined after being elected archbishop of Narbonne. As while both enterprises the venerable Arnold showed the best of his qualities of action man, in the first one he incarnated the worst of violence and fanatism that defined the holy war against the Occitans lords accused of heresy. Decided the victory of this crusade in the battle of Muret (1213), Arnold lost his primal protagonism, running down in a feudal figit for the dukedom of Narbone owing by lordly and, perhaps, familiar ambitions. Exceptional personality, the Cistercian Arnold Amalric is, of course, one of the protagonists of Medieval West in the early XIHI ${ }^{\text {th }}$ Century
\end{abstract}

En una abadía de la Orden del Císter, situada cerca de Lérida y llamada Poblet, vivía un hombre digno que era abad. Su sabiduría le valió para elevarse de dignidad en dignidad; de Poblet...se le hizo venir a la de Grandselve, y allí fue elegido abad; más tarde en otra asamblea, se convirtió en abad del Císter, porque era amado de Dios. Este muy santo hombre marchó también al país de los herejes; él les predicaba...pero cuanto más les rezaba allí, más se le tornaban ellos en burla, sin hacerle más caso que a cualquier idiota: iSin embargo él era legado del Papa, quien le había dado poderes bastante concretos para que pudiera destruir a gente tan despreciable! ${ }^{2}$.

Así describe el trovador navarro Guillermo de Tudela a Arnaldo Amalrico o Amalarico ( $\uparrow 1225)$, destacado protagonista de la Cruzada Albigense (12081229) y de la campaña contra los almohades que culminó en la gran victoria de Las Navas de Tolosa $(1212)^{3}$. Esta importante figura histórica ha quedado en un cierto segundo plano oscurecida por las de otros contemporáneos no menos relevantes. Su origen hispano, apuntado por la Cansó de Guillermo de Tudela, lo atestiguan también las actas del monasterio de Poblet y otras fuentes coetáneas como la Crónica Latina de los Reyes de Castilla, que asegura de él qui oriundus fuerat de Catalonia ${ }^{4}$. Sin embargo, el destacado papel de $\mathrm{Ar}-$ naldo Amalarico durante la Cruzada Albigense, desarrollada en el Languedoc y de desenlace tan decisivo para la formación de la Francia medieval, explica su absorción por la historiografía francesa y su abandono por la hispana, para la que ha quedado un tanto olvidado. Ambas razones motivan nuestro interés por Arnaldo Amalarico, del que ofreceremos un breve perfil biográfico e

2 Guillermo de TUdela, Chanson de la Croisade Albigeoise, ed. E. MARTIn Chabot, 3 vols. París, 1931-1961 ("Les Classiques de I'Histoire de France au Moyen Age"), vol. I, cap. ì(laisse 3).

3 Su nombre varía según șe cite en castellano, catalán o francés: Arnaldo-Arnoldo/ArnauArnaut/Arnaud/Amalarico-Amalrico/Amalric-Amalrich/Amaury.

4 Crónica Latina de los Reyes de Castilla, ed. L. CHARLo BREA, Univ. Cádiz, 1984, p. 29, lín. 22

La Personalidad lnternacional de los Papas

Hispania Sacra 48 (1996) 
ideológico a partir de algunas fuentes de la época y de los escasos trabajos historiográficos a dedicados a su vida.

\section{EL MONJE, EL ABAD, LA OCCITANIA CÁTARA (1196-1204)}

Nada sabemos de la vida del catalán Arnau Amalric antes de 1196. Ese año el oscuro monje Arnaldo fue elegido prior de la abadía cisterciense de Poblet (Tarragona) $^{5}$. Allí comenzó una fulgurante carrera que le convirtió en 1198 en abad de Grandselve y en noviembre de 1200 , por "su talento administrador y su gran celo por la fe", en el XVII abad del monasterio de Cîteaux y abad general (abad-padre) de toda la Orden. Como suprema cabeza del Císter, Arnaldo Amalarico obtuvo el liderazgo sobre diez mil monjes y el control de 600 abadías y encomiendas extendidas desde el Báltico a Sierra Morena y desde Inglaterra a Tierra Santa, convirtiéndose -observa M.H. Vicaire- en uno de los más poderosos hombres de gobierno de su época ${ }^{6}$.

Esta brillante ascensión religioso-política iba a continuar en el conflictivo ambiente de la Occitania de principios del siglo XIII, escenario entonces del enfrentamiento entre la Iglesia y la expansiva herejía cátara o albigense ${ }^{7}$. Frente a esta amenaza, el Papado contaba con la poderosa Orden del Císter,

5 J. FINESTRES Y DE MONSALVO recoge una escritura de fecha 20 de abril (12 calendas de mayo) de 1192 que trata de una concordia entre Poblet y el cabildo de Lérida (Arch. Cabildo de Lérida, Libro Verde falle. $n^{\circ} 370$ ) en la que Arnaldo ya era pijor de Poblet en esa fecha: Signum Arnaldi Amalrici, Prioris Populati, en Historia del Real Monasterio de Poblet, 4 vols., Barcelonn, 1765, vol. II, disert. 7, pp. 175-183; véase también Daunou, M., "Arnaud-Amaury, abbé de Citeaux, puis archevêque de Narbonne", Histoire Littéraire de la France, vol. XVIJ, París, 1832 (vol. XVIII, París, 1895).

6 VICAIRE, M.-H., "Les clercs de la Croisade", Paix de Dieu et guerre sainte en Languedoc au $X I T^{f}$ siècle, Cahiels de Fanjeaux 4 (1969), pp. 260-280, 265. Breve, pero muy interesante aproximación a la personalidad de Amaldo Amalarico; LABAL, P., Los cátaros. Herejía y crisis social, Barcelona, 1984; LEXAl, J., Los Cistercienses: ideales y realidad, Madrid, 1990, pp.136-138.

7 Sobre esta cuestión, véase entre otros muchos trabajos: BELPERRON, M., La Croisade contre les Albigeois, París, 1942; Cahiers de Fanjeaux, $n^{\circ} 3$ (1968) "Cathares en Languedoc"; $n^{\circ} 4$ (1969) "Paix de Dieu et Guerre Sainte en Languedoc au XIIle siècle"; $n^{\circ} 21$ (1986) "Les Cisterciens de Languedoc, XIlle-XIVe siècles", etc.; Delaruelle, E., Lîdée de Croisade au Moyen Age, Turín, 1980; DEVIC, C. DE-VAISSETE, J., Histoire générale du Languedoc, 8 vols., Toulouse, 1874-1889, vol. VI; Fliche, A.-MARTIN, V., Histoire de 1 Eglise, Paris, 1935, vol. II; GrifFe, E., Le Languedoc cathare au temps de la Croisade (1209-/229), París, P.U.F., 1973; LA8AL, op. cit.; MADAULE, J., Le dame albigeois et l'unité française, París, 1973; RoQUEBERT, M., L'épopée cathare, 4 vols., Tolosa, 1970-1989; Rousset, P., L'ídée de Croisade chez les croniqueurs d'Occident, Roma, 1955; THOUZELlER, Ch., Catharisme et valdeisme en Languedoc à la fin du XIJ e siècle et au début da XIII e siècle, París, 1969; Ventura Subirats, J., Pere el Catolic $i$ Simó de Montfort, Barcelona, 1960; WAKEFELD, W.L., Heresy, Crusade and Inquisition in Southern France, //00-/250, Londres, 1974. 
heredera de la labor antiherética realizada en el Midi por Bernardo de Claraval a mediados del siglo XII ${ }^{8}$. Desde 1200, esta misión será asumida en el "mundo cisterciense" por un "partido narbonés y catalano-provenzal hostil a la casa de Tolosa" en el que militaron, entre otros, Pedro de Castelnau, Raúl de Fontfroide, Fulco de Marsella, Gui de Vaux-de-Cernay y Arnaldo Amalarico ${ }^{9}$.

\section{EL LEGADO, EL PREDICADOR (1204-1208)}

El 31 de mayo de 1204 el papa Inocencio III (1198-1216) nombró a Arnaldo legado pontíficio en todo el Midi junto a Pedro de Castelnau y Raúl, monjes cistercienses de la abadía de Fontfroide. Su gran autoridad, prestigio y experiencia como abad de Grandselve, madre de todas las abadías cistercienses occitanas, y como abad general del Císter fueron las principales razones de esta nueva promoción. Ante la decadencia del clero meridional y el creciente éxito de los perfectos, Roma necesitaba "una especie de ortodoxia militante" que encarnarían "un teólogo riguroso" (Raúl), "un jurista rígido" (Pedro) y "un general impaciente por actuar" (Arnaldo Amalarico) ${ }^{10}$. A éste último se encargó extirpar la herejía en las provincias de Aix, Arles, Narbona y sus vecinas ${ }^{11}$.

Al principio, la Iglesia combatió la expansión cátara con medios pacíficos doctrinales plasmados en disputas dialécticas en las que destacaron los castellanos Diego de Osma y Domingo de Caleruega. Junto a ellos, Arnaldo Amalarico, hombre de religión total, de ciencia consumada, de santidad incomparable según la Hystoria Albigensis del cisterciense Pedro de Vaux-de-Cernay, reunió en 1207 un grupo de doce abades y treinta monjes para organizar la llamada "santa predicación" siguiendo —continúa el cronista-las opiniones del obispo de Osma ${ }^{12}$. Su objetivo era combatir a los cátaros con sus mismas armas -pobreza, humildad, "asistencia social"-y el enfrentamiento doctrinal y dialéctico con los perfectos. Fue en esas fechas cuando el abad del Císter presidió los famosos debates celebrados en Montreal y Pamiérs.

\& Foreville, R., "Arnaud Amalric, Archevêque de Narbonne (1 196-1225)", Guivernenent et vie de I'Eglise au Moyen Age. Recueil d'études, Variorum Reprints, Londres, 1979, pp. 129-146, 137. En datos y fechas seguimos con frecuencia este trabajo, el más completo sobre Arnaldo Amalarico.

* Biget, J.L.-Pradaller, M., Lart cistercien dans le Midi Toulousain, Cahiers de Fanjeaux $\pi^{\circ} 21$ (1986), pp. 363-364, n. 103.

10 ROQUEBERT, 1, 178; LABAL, 136-138.

II ForEville, 137.

12 Pedro Des VauX-DE-CERNAY, Histoire Albigerise, Nouvelle traduction française par P. Guébin et H. Majsonneuve, París, I95I, p. II, cap. ii (47), p. 20.

La Personalidad Internacional de los Papas

Hispania Sacra 48 (1996) 
En esas fechas, el abad-legado demostró su capacidad organizativa al realizar una "sistemática compartimentación de la provincia narbonense" con el fin de favorecer la campaña de predicación itinerante. Sin embargo, esta "predicación de la pobreza" dirigida por Santo Domingo, en la que ni Arnaldo ni los cistercienses creían, fue un fracaso ${ }^{13}$.

La autoridad de Arnaldo Amalarico al frente de la ortodoxia se hizo indiscutible tras la muerte de Raúl ( 7 de julio de 1207) y, sobre todo, a raíz del asesinato de Pedro de Castelnau a manos de un escudero de Raimundo de Saint-Gilles (1195-1222), VI conde de Tolosa y primer responsable para el clero católico de la expansión herética en Languedoc.

Este trascendental episodio sigue siendo una incógnita. Raimundo VI, responsable "oficial" del crimen no ganaba nada con la muerte de Pedro de Castelnau; Arnaldo Amalarico fue el "principal beneficiario" del crimen. Reflexionando sobre ambos hechos, $\mathrm{M}$. Roquebert llega a plantear que la implicación del abad-legado en el asesinato resulta más verosímil que la del propio conde de Tolosa. Lo importante de esta sugerente e indemostrable hipótesis es que la tortuosa personalidad del venerable Arnaldo permita su planteamiento. Lo que sin duda el tiempo se encargaría de demostrar es que "si Raimundo VI hubiera debido deshacerse de alguien, habría sido de Arnaldo Amalarico más que de Pedro de Castelnau"14

$\mathrm{El}$ asesinato del legado precipitó los acontecimientos. Inocencio III perdió la paciencia tras comprobar el fracaso de los medios pacíficos empleados hasta entonces y el 10 de marzo de 1208 predicó la cruzada contra los cátaros occitanos y los nobles que los toleraban ${ }^{15}$. Movilizados los cistercienses, Arnaldo Amalarico, que Dios amaba tanto — según la Canción-16 ${ }^{16}$, fue encargado de predicar la cruzada en las provincias de Aix, Arles, Narbona, Vienne, Auch y Embrun junto a sus nuevos colaboradores, los obispos Hugo de Riéz y Navarro de Couserans. Tras años de predicación, porque el Abad estaba ple. namente al corriente de la situación y de las mentiras del conde [Raimundo VI], Arnaldo Amalarico se convirtió en la suprema autoridad de la Cruzada contra la herejía ${ }^{17}$. Junto a él, los maestros Milon y Thédise, dos colaboradores "de apasionada personalidad" y hostiles a Raimundo VI, arruinarían "la política moderada y leal de Inocencio III"18.

13 LABAL, 142-147.

14 ROQUEBERT, l, 216-219.

15 P.VAUX-DE-CERNAY, III, i(64), 3 ! .

16 Chanson, $\mathrm{i}, \mathrm{i}(4)$.

17 P.VAUX-DE-CERNAY, III, i(71), 34.

18 Fliche, A.-MARTIN, V., II, iv, 127-128. 
Parece claro que el abad del Císter jugó un papel decisivo en el endurecimiento de la política pontificia. Valedor de la política de fuerza, "para cavar entre él [Raimundo VI] y la Iglesia este irremediable foso que hará posible la conquista militar del condado de Tolosa y la desposesión del conde, el abad del Císter se esforzará alternativamente, ya en no aplicar las directivas pontificias que abrían la vía a un acercamiento, ya en influir en el propio Inocencio III para que endureciese su posición, no vacilando llegado el caso en engañarle"19.

\section{EL "ALMA" DE LA CRUZADA ALBIGENSE (1209-1212)}

El llamamiento papal atrajo a gentes de todo el Occidente, especialmente de Île-de-France, Normandía, Bretaña, Germania y norte de Italia. Estos contingentes cruzados se concentraron en Lyon en la primavera de 1209. El 24 de junio Arnaldo Amalarico asumió el mando supremo de la expedición bajo la dirección espiritual y material de la teocracia pontificia. Será así el "jefe de la cruzada"20. Según Vaux-de-Cernay, Arnaldo representó desde entonces el papel de campeón espiritual del "Campo del Bien"21: Tú conducirás los ejércitos contra la gente pérfida fueron las palabras que el papa dirigió entonces a Arnaldo según la Canción de la Cruzada de Guillermo de Tudela ${ }^{22}$.

El pímer objetivo del Dei exercitus -así llama a los cruzados el cronista católico Guillermo de Puylaurens- fue el vizcondado de Béziers-CarcasonaAlbi, cuyo señor, Raimundo-Roger de Trencavel, estaba acusado de complicidad con los herejes. En julio de 1209 comenzó el asedio de Béziers, cuyo recuerdo quedará vinculado al de Arnaldo Amalarico por el legendario episodio que allí le fue atribuido al religioso y hábil caudillo de los miles Christi ${ }^{23}$. Al iniciarse el asalto de la ciudad, se cuenta que le fue consultada la suerte que correrían los habitantes del lugar que se habían confesado católicos y no partícipes de la herejía; ante la dificultad de distinguir a unos de otros, Amaldo Amalarico contestó: Matadlos a todos; Dios reconocerá a los suyos ${ }^{24}$.

\footnotetext{
19 ROQUEBERT, I, 216-219.

20 FOREVILLE, 138.

21 P.VAuX-DE-CERNAY, II, ii(40), 18 y ss.

22 Chanson, I, i(6).

23 Guillermo De Puylaurens, Chronique, ed. Beyssier. Université de Paris, Bibl. Faculté des Lettres. "Troisjèmes Mélanges d'Histơire du Moyen âge", París, 1904, p. 129.

24 Cesarjus De Heisterbach, Dialogus Miracolorum, ed. J. STRange, 2 vols., Colonia, 185!, libro 5, cap. 21 ; P. VAUX-DE-CERNAY, III, ji(91), 42, n. 4; sobre esta anécdota véase el reciente trabajo de BERLJOZ, J., Tuez-les tous, Dieu reconnâtra les siens. La Croisade contre les Albigeois vue par Césaire de Heisterbach, Portet-sur-Garonne, Loubatières, 1994.
} 
Esta célebre anécdota es uno de los más claros ejemplos de la "mentalidad cruzada" —definición de R. Barkai-que dominó los acontecimientos sucedidos en el Languedoc entre 1209 y $1229^{25}$. Su certeza histórica es problemática, pues el cisterciense Cesáreo de Heisterbach, el primero en citar este hecho en su Dialogus Miraculorum (1219-1223), lo consideró ya un rumor. Aunque seguramente el abad-legado jamás pronunció esa frase, lo importante es que -como afirman Guébin y Maisonneuve- Arnaldo Amalarico sí que "hubiera sido capaz de decirla"26. En cualquier caso, el 22 de julio de 1209 tuvo lugar, peccatis exigentibus según Puylaurens, la masacre de la población de Béziers a manos de los cruzados ${ }^{27}$. El propio Arnaldo, inspirador de la acción, comunicó al papa la muerte de "cerca de veinte mil" personas, limitándose a dar gracias al Cielo por este inesperado triunfo ${ }^{28}$. La matanza de Béziers, tan salvaje que Guillermo de Tudela no creía recordar nada semejante desde tiempos de los Sarracenos, tuvo un efecto psicológico y político demoledor en toda Occitania, convirtiéndose en buen reflejo de lo que sería desde entonces la Cruzada Albigense ${ }^{29}$.

El ejército cruzado continuó sus conquistas en la zona después de que, a petición de Arnaldo, Hugo de Riéz y el maestro Milon, Inocencio III instituyera el diezmo de cruzada para evitar su disolución. Tras Béziers, los cruzados sitiaron Carcasona (28-julio/l-agosto), donde también sobresalieron las dotes de mando de Arnaldo Amalarico. Cuenta Vaux-de-Cernay que, tras la destrucción de Ios molinos de la región y observando la abundancia de pan entre los cruzados, los herejes decían también, a causa de esto, que el Abad del Cister era un encantador y que habia traído a los demonios bajo apariencia humana, porque parecía que a los cruzados no les faltaba de nada ${ }^{30}$. Poco después capituló Carcasona y el vizconde Trencavel cayó preso: las "maniobras" atribuidas a Arnaldo en ambos hechos y en la sospechosa muerte de aquél enriquecieron la ya muy sombría imagen que del legado tenían los meridionales.

Durante Ia Cruzada, la autoridad de Arnaldo Amalarico respaldó siempre las decisiones más importantes de la empresa antiherética. Buen ejemplo de ello fue la conferencia en la que el legado, el padre y el jefe de la Cruzada, inspiró la elección de Simón de Montfort (h. 1160-1218) como nuevo señor de

2.5 BARKAI, R., Crístianos y musulmanes en la España medieval (El enemigo en el espejo), Madrid, Rialp, 1991, pp. 205 y ss.

26 P.VAUX-DE-CERNAY, Introducción, XVI

27 PuYlaurens, 131.

28 Carta fechada a finales de agosto de 1209, MiGNE, J., Patrología Latina, París, 1844-, CCXV1, 137-141. La cifra es exagerada, pero ilustrativa de lo sucedido.

29 Chanson, I, $x(69)$.

30 P.VAuX-De-CeRnaY, III, ii(97), 44. 
las tierras de los herejes y jefe militar de la cruzada (agosto de 1209) ${ }^{31}$. Entre marzo y junio de 1210 , mientras los cruzados continuaban sus acciones bélicas en la región, el legado dirigió la predicación y organización de la "Cofradía Blanca" junto al obispo Fulco de Tolosa, antiguo mercader y trovador marsellés al que el anónimo tolosano continuador de la Canción de la Cruzada llamó el obispo felón ${ }^{32}$. El 27 de junio de ese año la legación de Arnaldo fue ampliada a las provincias de Burdeos, Besançon, Vienne, a seis diócesis de la provincia de Bourges y a la diócesis de Pamplona. También entonces reabrió el procedimiento iniciado en 1204 contra el catalán Berenguer, arzobispo de Narbona y responsable del avance de la herejía en su provincia $^{33}$.

El carácter belicoso y fanático del legado quedó otra vez de manifiesto durante las negociaciones con Guillermo, señor de Minerva, que ese verano de 1210 estaba asediada por los cruzados: dice Vaux-de-Cernay que el Abad fue extremadamente contrario a la propuesta de capitulación planteada por Simón de Montfort, pues él deseaba vivamente la muerte de los enemigos de Cristo, pero como era monje y sacerdote no se atrevía a hacerles morir ${ }^{34}$. Esta actitud, que Vicaire considera "característica" de Amaldo, es propia del hombre de fe fanatizado contra los que considera enemigos de su Dios, del caudillo de una empresa de "purificación" y conquista basada en la guerra santa y en la destrucción a toda costa del disidente religioso ${ }^{35}$. Esta "piadosa hipocresía", que escandalizó a muchos, correspondía a alguien que consideraba su misión un designio divino y a sí mismo un hacedor de la voluntad de Dios por mandato directo de su representante en la tierra, el Papa de Roma ${ }^{36}$. No en vano, el abad del Císter fue considerado, en palabras del cronista cisterciense, el principal animador después de Dios del "negotium Christi"'s7.

Pero la Cruzada era también un negotium fidei et pacis y en búsqueda de esa Paz de Dios - que recordemos no contaba para los que estaban al margen de la Iglesia- Arnaldo jugó el papel de mediador y árbitro entre los poderes que se disputaban el control político y militar del Languedoc. Ello ocurrió en

31 Acta de Vizconde de Carcasona y Béziers firmada por Montfort, Parologia Latina, ed. J.P. MIGNe, París, 1857-1866, t. CCXVI, c. 142; citada en Ventura I SubiRats, J., Pere el Catolic, XII, 107; P.VAUX-DE-CERNAY, 1I1, ii(101), 45; ForeVILLE, 130; VENTURA, 97-101.

32 Chanson, III, (155); sobre este personaje véanse STRONSKY. S., Le troubadour Folquet de Marseille, Cracovia, 1910 y CABAu, P., "Foulque, marchand et trovadour, de Marseille, moine et abbé du Thoronet, évêque de Toulouse (v. 1155/1160-25-XII-1231)", Cahiers, 21, 151-179.

33 FOREVILLE, 139.

34 P.VAUX-DE-CERNAY, lil, iii(154), 65.

35 VICAIRE, 267.

36 P.VAUX-DE-CERNAY, Introducción, XVI.

37 lbidem, III, iii (195), 80.

La Personalidad Internacional de los Papas Hispania Sacra 48 (1996) 
las fracasadas conferencias de Narbona y Montpellier (22 de enero y 6 de febrero de 1211) con participación de Simón de Montfort, Raimundo VI de Tolosa, el obispo Raimundo de Uzès y el rey Pedro II de Aragón (1196-1213), tradicional señor de muchos territorios occitanos ${ }^{38}$.

Ya entonces, para los señores meridionales aliados de Raimundo VI de Tolosa y más o menos vinculados a la herejía, Arnaldo Amalarico se había convertido en una auténtica "bestia negra", en la cabeza visible de una expedición extranjera -."francesa"- que arrasaba tierras y vidas en nombre de la Iglesia Católica. En Vaux-de-Cernay se observa que el sentimiento de rencor hacia Arnaldo, y por extensión hacia los monjes blancos, era patente entre los meridionales: el conde de Tolosa y sus cómplices, en efecto, detestaban por encima de todo a los monjes de esta Orden, y particularmente a los de esta abadía [Grandselve], porque el Abad del Císter, legado de la Sede Apostólica, principal responsable, según ellos, de su desposesión, había sido abad de este monasterio ${ }^{39}$.

Tras las negociaciones, una nueva expedición cruzada fue reclutada en el norte de Francia. Como cabeza espiritual de la Cruzada, Amaldo siguió acompañando al conde de Montfort durante la conquista del Albigeois y el primer asedio de Tolosa (mayo-junio de 1211) (0. $^{4}$.

\section{EL ARZOBISPO DE NARBONA (MARZO DE 1212)}

Tras dos largos e intensos años dirigiendo la lucha contra la herejía, la carrera de Arnaldo Amalarico alcanzó una nueva meta: el 12 de marzo de 1212 fue elegido arzobispo de Narbona en sustitución del denostado Berenguer ${ }^{41}$. Este hecho representaba un paso más en el proceso de "ocupación" de las principales sedes occitanas por parte de cistercienses meridionales fieles a Roma y vinculados a la Cruzada, ya que anteriormente el legado Thédise había sido elegido obispo de Agde y Gui de Vaux-de-Cernay, tío del cronista, obispo de Carcasona ${ }^{42}$. Confirmado por el obispo-legado Raimundo de Uzès, el vizconde Amalric de Narbona le prestó homenaje en presencia de los obispos de Béziers, Tolosa, Maguelone, Agde, Elne, Lodève y casi todos los sufragáneos de Narbona, Couserans, Comminges, de la provincia de Auch y de los abades de Saint-Paul y Saint-Aphrodise de Narbona, además del clero y del pueblo.

\footnotetext{
38 Ibiden, (195) , 80-81; (210-211), 85-86; FOREVILLE, 140.

39 Ibidem, III, iv(277), 113 .

41 ForeViLLE, 140-141.

41 P.VAux-De-Cernay, IIt, vii(299), 121.

42 LEKAY, J., Las cistercienses: ideales y realidad, Madrid, 1990, cap. V, pp. 73-75.
} 
El 13 de marzo Arnaldo tomó posesión con consentimiento de sus sufragáneos y de los co-legados. Según Fliche-Martin, al hacerlo "usurpó" el título ducal de Narbona, vacante por desposesión de Raimundo VI de Tolosa, su tradicional poseedor, hecho que más adelante tendría sus consecuencias ${ }^{43}$. Esta promoción supuso - según R. Foreville- el inicio de una política o actitud nueva en la evolución de Amaldo Amalarico ${ }^{44}$. Sin embargo, el nuevo arzobispo de Narbona, el más sabio y el más virtuoso que jamás haya llevado la mitra según Guillermo de Tudela, no iniciaría sus actividades en el Languedoc ${ }^{45}$.

\section{El "CRUZADO": la CAMPAÑa de las Navas de Tolosa (Mayo-JUlio de $1212)^{46}$}

En enero de 1212, y a petición del rey Alfonso VIII de Castilla (11581214), Inocencio III solicitó ayuda al clero francés y provenzal de cara a la campaña que el rey castellano organizaba contra los almohades. En plena crisis de la Cruzada Albigense, Arnaldo Amalarico asumió el papel de "hombre de acción", su preferido, y no dudó en acudir a la llamada del papa ${ }^{47}$.

${ }^{43}$ FLICHE-MARTIN, IV, 132.

44 FOREVILLE, 13I.

45 Chanson, $\mathrm{I}, \mathrm{i}(7)$.

4n Sobre esta céestión, véase GonzÁlez, J., El reino de Castilla en época de Alfonso VIII, 3 vols., Madrid, 1960, vol. I, pp. 981 y ss; GoÑl GazTAmBide, J., Historia de la bula de Cruzada en España, Vitoria, 1958, pp. 110-132; HuICI MIRANDA, A., Estudio sobre la batalla de las Navas de Tolosa, Anales del Instituto General y Técnico de Valencia, Valencia, 1916; id, Las gramdes batallos de la Reconquista durante las invasiones africanas (almorávides, almohades, benimerines), C.S.I.C., Madrid, 1956, pp, 219-327; RUIZ DOMÉNEC, J.E., "El significado histórico de la batalla de Las Navas de Tolosa y sus consecuencias", en Historia General de España y América, vol. IV (La España de los Cinco Reinos), Madrid, 1984, pp. 585-589; y MARTínez D(EZ, G., Alfonso VIII, rey de Castilla y Toledo, "Col. Corona de España", XXI, "Serie Reyes de León y Castifla", Burgos, La Olmeda, 1995, pp. 175-213. Sobre algunas cuestiones ideol6gico-mentales y militares relacionadas con la batalla de Las Navas de Tolosa, véanse mis trabajos: ALVIRA CABRER, M., "Dimensiones religiosas y liturgia de la batalla plenomedieval: Las Navas de Tolosa, 16 de julio de 1212", XX Siglos, $\mathrm{n}^{\circ} 19$ (Madrid, 1994), pp. 33-46; id. "La muerte del enemigo en el Plenomedievo: cifras e ideología (El modelo de Las Navas de Tolosa)", Hispania, vol. LV/II, n 190 (Madrid, 1995), pp. 403-434; id., "La concepción de la batalla como duelo y la propaganda de cruzada en Occidente a principios del siglo XIII: El desafín de Miramanolín a la Cristiandad antes de la batalla de Las Navas de Tolosa (16 de julio de 1212)", Heresis, Centre dÉtudes Cathares, Carcasona (en prensa); id., "De Alarcos a ias Navas de Tolosa: idea y realidad de los origenes de la batalla de 1212", Actas de Alarcos 1/95. Congreso Internacional VII Centenario de la Batalla de Alarcos, Universidad de Castilla-La Mancha, Ciudad Real (en prensa); id., "El desafio del Miramamolín antes de la batalla de Las Navas de Tolosa (1212). Fuentes, datación y posibles orígenes" en Archivoss Leoneses, León (en prensa).

47 VICAIRE, 266

La Personalidad Internacional de los Papas

Hispania Sacra 48 (1996) 
Las razones de esta decisión son múltiples. En primer lugar, el abad del Císter era cabeza de la Orden Militar de Calatrava, cuyo convento mayor estaba desde 1198 en la fortaleza de Salvatierra. El asedio y conquista de la sede de los calatravos por el ejército almohade en el verano de 1211, origen inmediato de la campaña de 1212, "conmovió, sin duda, a los cistercienses".

A ello debe añadirse que el Capítulo General del Císter tenía asumido un importante papel en la lucha de los reinos peninsulares contra los musulmanes. Desde la gran derrota castellana de Alarcos (1195) -observa D.W. Lomax--, el temor al peligro almohade había hecho resurgir el interés de Europa por la Reconquista: los príncipes hispanos (sobre todo Alfonso VIII) se encargaron de difundir este interés a través de dicha institución, hasta el punto que fue el monarca castellano quien primero utilizó el Capítulo General cisterciense como "medio de comunicación social". La predicación de la cruzada, las indulgencias papales y las embajadas castellanas de finales de 1211 y principios de 1212 coincidieron con la cierta "mentalización" que, gracias a la labor de cistercienses y trovadores occitanos, Europa (especialmente la mediterránea) experimentaba desde los primeros años del siglo en favor de un gran enfrentamiento contra los almohades ${ }^{48}$.

Además de estas razones, Foreville añade otras también importantes como su gran celo cruzado - demostrado hasta el fanatismo contra los herejes albigenses-, la conciencia de la tradicional afinidad de su nueva provincia - la Narbonense-- con las tierras ibéricas, el mantenimiento de estrechos lazos del ex-abad de Poblet con los acontecimientos hispánicos, y quizá, la convicción personal, motivada por su reciente consagración arzobipal, de sentirse llamado a realizar "grandes cosas" 49 .

Una causa más, mucho menos loable, fue apuntada por Guébin y Maisonneuve: Arnaldo debía mantener ocupado al rey Pedro II de Aragón, para que éste no pudiera auxiliar a su cuñado Raimundo VI de Tolosa en el conflicto del Languedoc. Este móvil podría ser verosímil en virtud del carácter y comportamiento demostrados por Arnaldo durante su legación, pero, sin desdeñarlo, resulta poco firme. Según las fuentes hispanas la participación de Pedro II en la campaña contra los almohades se confirmó en Cuenca entre octubre y noviembre del año 1211, por lo que parece poco probable que el rey de Aragón pusiera entonces sus ojos en la guerra del Languedoc. Además, la convocatoria de Inocencio III al clero francés y provenzal está fechada el 31 de ene-

48 LOMAX, D.W., "La conquista de Andalucía a través de la historiografía europen de la época", en Andalucia entre Oriente y Occidente (/236-1492), Actas del V Coloquio internacional de Historia Medieval de Andalucín, Córdoba, 1986, pp. 38-39. Sobre esta cuestión, véase MAHN, J.B., L'Ordre cistercien et son gouvernement, París, 1951, pp. 173-216, esp. p. 241.

49 FOREVILLE, 131. 
ro de 1212, es decir, después de que Pedro II confirmara a Alfonso VIII su voluntad de acudir a la campaña ${ }^{50}$.

Lo sucedido en 1212 lo cuenta así el propio Arnaldo: Por las indulgencias que el Papa, Vicario de Jesucristo, concedió a todos los que acudiesen a la guerra en socorro de la cristiandad española, concurrieron de todas las partes del mundo fieles cristianos a Toledo, donde por edicto de los Reyes de Castilla y Aragón debian retmirse en la octava de Pentecostés ${ }^{51}$. Ya antes de su llegada la fama de Arnaldo Amalarico como "campeón de la fe" contra Ia herejía era bien conocida en la Península. En su Historia de rebus Hispaniae, el arzobispo de Toledo Rodrigo Ximénez de Rada, organizador, testigo y cronista de la empresa de 1212, dice: Vino también...el venerable Arnaldo, quien habiendo desempeñado por algún tiempo el priorato del Císter, gobernaba por entonces la Iglesia de Narbona. Éste, empujado poco antes por su celo de la fe católica en contra de quienes osaron blasfemar con boca sacrílega el nombre del Señor y de la lglesia en Narbona y las provincias limítrofes, alentó los corazones de los fieles para que se armaran con la enseña de la cruz contra las artimañas de los herejes. Y por la gracia de Dios sucedió que, donde la prédica, desdeñada, no dio fruto, segada la herejía con la hoz de la cruz, la fe católica creció con felicidad día a día; y arrasadas Béziers y Carcasona, la sangre de los blasfemos fue exprimida por el fuego aniquilador y la espada vengadora en la era 1246 [1209]52. También lo confirman, entre otras, la Crónica Latina de los Reyes de Castilla, la Carta de Alfonso VIII al Papa Inocencio III, la Carta de Blanca de Castilla y la Crónica del cisterciense Alberico de Trois-Fontaines ${ }^{53}$.

Al término de la campaña, Arnaldo relató lo ocurrido en una larga y detallada carta dirigida al Capítulo General del Císter que fue leída el 13 de sep-

50 Gonzalez, 997 y ss; MANSILLA, D., "La documentación pontificia de lnocencio 11 (1 198 (216)", Monumenta Hispaniae Vaticana, t. I, n. 396, Roma, 1955, $\mathrm{n}^{\circ}$ 468, pp. 497-498.

s1 Los Anales de la abadía cisterciense de Waverley (Surrey-Inglaterra) datan la carta en Toledo sabbato ante assumptionem beatae Virginis Mariac, esto es, el sábado II de agosto de 1212, fecha que se ajusta con precisión a los hechos. Puede consultarse en Recucil des Historiens des Gathes et de la France, vol. XIX (París, 1880), pp. 250-255; HuICI, Estudio, Fuentes cristianas ap. JI, 170175, 171; Gaspar Ibañez de Segovia Peralta Y Mendoza, Marqués de Mondejar, Memorias históricas de la vida y acciones del Rey D. Alonso el Noble, octavo de esie nombre, Madrid, 1783, ap. CII].

32 Jimenez De Rada, R., Historia de los Hechos de España, ed. J. FernÁndez Valverde, Madrid, 1989, libro VIII, cap. ii, pp. 308-309.

53 Crónica Latina, 27, 20-22; Carta de Alfonso VHI a Inocencio HI: Gonzalez, III, $\mathrm{n}^{\circ} 897$, 567; HUICI, Estudio, Fuentes cristianas ap. II, 166; MONDEJAR, ap. XII y XCVIII; Carta de Blanca, hija de Alfonso VII y reina de Francia a Blanca, condesa de Champagne y hemana de Sancho VII de Navarra: Recueil, XIX, 255-256; y Crónica de Alberico de Trois-Fontaines, ed. HuICI, Estudio, Fuentes cristianns ap. VI, I81; MONDEJAR, ap. CXXII.

La Personalidad Internacional de los Papas

Hispania Sacra 48 (1996) 
tiembre de $1212^{54}$. Esta carta, fuente de primera magnitud en relación con la jornada de Las Navas, es fruto de una de las más peculiares características de Arnaldo Amalarico: la costumbre de enviar al papa partes circunstanciales y copias de actas de todos los hechos importantes de su legación. A esta cualidad, que M.H. Vicaire llama "sentido de los archivos", la historiografía moderna debe valiosas fuentes como este "parte de guerra" de 1212 y la rica documentación que Pedro de Vaux-de-Cernay recogió en su Hystoria Albigensis $^{55}$. Además, la circulación de esta carta en el "mundo cisterciense" permitió la difusión de la gran victoria hispano-cristiana en gran parte de Occidente ${ }^{56}$.

En su relato, Arnaldo cuenta que no sólo reclutó tropas francesas y occitanas para la campaña - caballeros e infantes bien armados de las diócesis de Lyon, Vienne y Valentinois-, sino que también las acaudilló y dirigió hasta Toledo, punto de reunión de las huestes cristianas. El contingente cruzado de Arnaldo Amalarico (entre 100-150 caballeros además de los peones) llegó el 3 de junio de 1212 -Foreville dice el martes 5-, siendo recibido como merecía por Alfonso VIII y el arzobispo toledano ${ }^{57}$. Arnaldo explica que en Toledo trató con los Reyes del bien de la república cristiana y de la venida del Rey de Navarra, que entonces estaba enemistado con el rey de Castilla; porque en nuestro viaje nos habíamos detenido en la residencia del Rey de Navarra --el domingo 20 de mayo, según Foreville-para inducirle a venir en socorro del pueblo cristiano ${ }^{58}$. El legado Arnaldo, cuya autoridad se extendía desde 1210 a la diócesis de Pamplona, llevó a cabo esta misión siguiendo las tradicionales pautas de la política pontificia: paz entre los cristianos y guerra contra los "enemigos de Dios". Sin que podamos saber el éxito de la entrevista, lo cierto es que, a última hora, Sancho VII de Navarra (1196-1234) —en palabras de Ximénez de Rada- - no enajenó del servicio de Dios la honra de su valentía cuando se aproximaba el momento crítico ${ }^{59}$.

La campaña comenzó el miércoles 20 de junio de 1212. El día 24 los $u$ tramontanos, que marchaban en primer lugar, llegaron a Malagón, castillo musulmán donde - cuenta Arnaldo- dióse muerte a todos los que se encontraron, excepto unos pocos. Tres días después fue asediada la fortaleza de Calatrava, antigua sede de la Orden, que fue rendida el domingo I de julio por capitulación para evitar —continúa- dilaciones y la muerte de cristianos.

s4 El Capítulo General del Císter se reunió el I4 de septiembre, dín de la Exaltación de la Santa Cruz, hasta 1209. En 1210 el Capítulo decidió que tas sesiones se celebraran la víspera de esta fiesta, es decir, el día 13. En 1233 las sesiones pasaron al día 12 de septiembre, MAHN, 174.

55 Sobre la carta de Arnaldo Amalarico, véase la nota 51 ; VICAIRE, 266.

sf Sobre la batalla de Las Navas en la historiografín europea, véase LOMAX, 38 y ss.

57 VICAIRE, 266; JIMÉNEZ DE RADA, VIII, ii, 309, 18-19.

sR ForeviLLE, 141; HuICI, Estudio, Fuentes cristianas ap. IIl, 171.

s9 JIMENEZ DE RADA, VIII, vi, 315, 64-65. 
Allí, el prestigio y autoridad de Arnaldo no pudieron impedir la retirada del grueso de las tropas transpirenaicas. El arzobispo de Narbona, que en su carta "sobrevuela" este hecho, afirma: créese que serían los que se volvieron con los Obispos [de Burdeos y Nantes] más de cincuenta millo. Con unos pocos, sin apartarse nunca del bien - según Ximénez de Rada-, el caballero de origen castellano Teobaldo de Blazón y Arnaldo Amalarico, que era oriundo de Cataluña - precisa entonces la Crónica Latina-, permanecieron junto al ejército cristiano ${ }^{61}$. Además de las razones ya expuestas, ¿influiría también en su decisión de acudir y, ahora, permanecer en la empresa peninsular esta condición de "hispano" que el anónimo autor de la Crónica Latina de los Reyes de Castilla parece querer asociar explícitamente en ambos personajes?

Arnaldo Amalarico participó en todos los consejos militares y decisiones importantes de la campaña de 1212, pero parece exagerado considerar con la profesora Foreville que el arzobispo de Narbona se constituyera, como había ocurrido en Languedoc, en "l’âme de la croisade"62. Con todo, no cabe duda que Arnaldo contribuyó con su experiencia, autoridad, fama y ejemplo al éxito de la empresa de Las Navas de Tolosa. Buena muestra de ello sería el "silenciado" intento de Alfonso VIII de desviar la cruzada contra su tradicional enemigo Alfonso IX de León (1188-1230), hecho que se cita en la carta de Blanca de Castilla, princesa de Francia e hija del monarca castellano. El arzobispo demostró entonces su voluntad e intención apoyando, junto a Pedro II de Aragón, la negativa del rey Sancho VII de Navarra a moveret arma contra Christianos, sed contra Sarracenos ${ }^{63}$.

A lo largo de su relato Arnaldo procuró destacar a las tropas que él mismo había reclutado. El 11 de julio, llegados los cristianos al Puerto de Muradal, paso de Sierra Morena y puerta de las tierras andalusíes, cuenta el Narbonés que los de Vienne y el Poitou, que estaban presentes, y aunque pocos, se opusieron con tal valor a los sarracenos, que los persiguieron más allá del agua de que nos querian privar ${ }^{64}$. Después de estar bloqueados en el accidentado Paso de la Losa, los cristianos lograron descender la Sierra y llegaron frente el campamento almohade, situado al otro lado de los llanos abarrancados de Las Navas de Tolosa (Jaén). Sobre esta cuestión es importante observar que, a diferencia de las fuentes castellanas, Arnaldo no mencionó nada sobre el célebre episodio del providencial "pastor de Las Navas".

\footnotetext{
6n Huicl, Estudio, Fuentes cristianas ap. [II, 171-172.

61 JIMENEZ DE RADA, VIII, vi, 314-315; Crónica latina, 29, 19-22.

62 FOREVILLE, 132.

63 Recueil, XIX, 255-256.

64 HutCl, Estudios, Fuentes cristianas ap. III, [72.
}

La Personalidad Internacional de los Papas Hispania Sacra 48 (1996) 
Durante dos días los cristianos descansaron y observaron a los almohades, quienes - dice Arnaldo- torneaban con los nuestros, no al modo de los franceses, sino según su costumbre de tornear con lanzas o cañas con el fin de provocar la batalla. En su carta, Amaldo combina informaciones como ésta con preciosos comentarios que permiten conocer el exaltado ambiente que rodeó el gran choque de Las Navas de Tolosa. El lunes 16 de julio de 1212, el tercer día día de alegría, día que hizo el Señor, día por siglos memorable en palabras de Amaldo, los cruzados salieron al campo antes que calentase el sol y formaron para el combate en tres grandes cuerpos al mando de los tres reyes ${ }^{65}$. Sobre el lugar que ocupó Arnaldo en la batalla, sólo Blanca de Castilla ofrece un dato preciso: In prima acie fuit Didacus Lupi [Diego López de Haro, señor de Vizcaya] et Garcias Romanus [García Romero, noble aragonés] et Abbas Cisterciensis, cum CCC militibus hinc et inde collectis ${ }^{66}$.

Iniciada la batalla, el poderoso ataque de los cristianos se vio frenado por los cuerpos almohades que protegían la cólina en la que estaba el Miramamolín al-Nasir. Arnaldo explica cómo el contraataque musulmán puso en gran peligro la resistencia de los cruzados de modo que casi todo el ejército que estaba antes del último haz, excepto algunos nobles españoles y ultramonta. nos, parecía huir. Grande fue el temor de muchos de los nuestros, no defraudase el Señor aquel día nuestras esperanzas. El arzobispo de Narbona interpreta los hechos en función de la ideología de Cruzada dominante entonces: es de creer que esto sucedió para reprimir la soberbia de los nuestros y para que al ver a nuestros soldados armados no nos atribuyésemos la victoria a nosotros...sino que la atribuyésemos a Nuestro Señor Jesucristo y a la Cruz, que ellos habian escarnecido y que los nuestros llevaban en el pecho...

Arnaldo Amalarico cumplió entonces con la labor encomendada en la guerra a los oratores: Nosotros al ver a los cristianos en fuga comenzamos a recorrer el ejército y a exhortar a los fugitivos a detenerse. En ese momento tuvo lugar la decisiva carga de los cuerpos de reserva al mando de los reyes Alfonso VIII de Castilla, Pedro II de Aragón y Sancho VII de Navarra: detuviéronse algunos por nuestros ruegos, otros volvieron a la pelea, y no sólo fueron rechazados los sarracenos, que seguian a los cristianos, sino que además los que estaban en el haz tan fuerte fueron vencidos y muertos. Desde aquel momento huyó irreparablemente el ejército de los sarracenos en pos de su rey, el Miramamolín, que ya antes había huido... El "milagro" obrado por Dios en Las Navas de Tolosa tuvo para Arnaldo dimensiones extraordinarias: Fueron en su alcance por cuatro leguas largas, y tantos mataron en la batalla

65 Ibidem, 172-173.

66 Recueil, XIX, 255-256. 
y después de ella, que fueron muertos sesenta mil y aún más, según se piensa. iY cosa admirable: según creemos de los nuestros no murieron cincuenta! ${ }^{67}$.

La gran victoria cristiana de $\mathbf{1 2 1 2}$ fue anunciada así a sus hermanos por el arzobispo de Narbona: Os anunciamos una nueva de gran alegría, porque el Miramamolín, rey de Marruecos, que, según hemos oído a muchos, había declarado la guerra a todos los que adoran la Cruz, ha sido vencido y puesto en fuga en batalla campal por los adoradores de la Cruz. En el mismo relato, Arnaldo muestra con absoluta claridad su concepción del mundo, su mentalidad de hombre de fe imbuido de un fuerte espíritu de cruzada y la certeza de su misión a ambos lados de los Pirineos: Bendito sea por todo Nuestro Señor Jesucristo, que por su misericordia ha concedido en nuestros tiempos, bajo el feliz apostolado del Papa Inocencio, la victoria a los católicos cristianos sobre tres clases de hombres petulantes y enemigos de su santa Iglesia: los cismáticos orientales, los herejes occidentales y los sarracenos meridionales... Fue esta batalla el año del Séñor 1212, a I6 de Julio, lunes, día de Santa Magdalena, en el sitio llamado Navas de Tolosa y que ahora está en poder de los cristianos por la gracia de Dios; para que entiendan y teman otro tanto, si no se arrepienten, los herejes tolosanos ${ }^{68}$.

Legado de la Cruzada contra la herejía, Arnaldo Amalarico no olvidó esta lucha cuando acudió a la Península. Convencido de la intervención de Dios en los asuntos de los hombres, el ex-abad del Císter cambió de marco geográfico y de misión, pero no de enemigo - "el otro"--, pues para él y para los que como él concebían el mundo, la lucha en defensa de la Christianitas no distinguía entre infieles (musulmanes), cismáticos (bizantinos) y herejes (cátaros). En el Languedoc ya lo había demostrado.

Tras la batalla, los cruzados ocuparon Vilches, la evacuada Baeza y el 23 de julio sitiaron la populosa Úbeda, repleta de refugiados. Allí el abad de Císter se unió a los otros prelados para rechazar un trato con los musulmanes que era contrario a la ley de Dios, por lo que por disposición divina la ciudad fue arrasada y la población cautivada ${ }^{69}$. En úbeda una enfermedad infecciosa puso fin a la expedición cruzada.

Tras esta gran victoria, Arnaldo Amalarico siguió manteniendo ante Roma su importante vinculación con los sucesos hispanos. En la carta Cum iam captis (15 de enero 1213), Inocencio III todavía ordenará a su legado hacer frente a una temida contraofensiva de los derrotados almohades en colaboración con

67 HuICI, Estudios, Fuentes cristianas ap. III, 173-174.

68 Ibidem, 170 y 174 .

69 Ibidem, 175 .

La Personalidad Internacional de los Papas Hispania Sacra 48 (1996) 
Pedro II de Aragón ${ }^{70}$. Sin embargo, la conflictiva situación en Languedoc reclamó de nuevo toda su atención.

TRIUNFO Y FRACASO EN LA CRUZADA CONTRA LA HEREJÍA: LA BATALLA DE MURET (FINALES DE 1212-SEPTIEMBRE DE 1213)

Vasallo de Roma desde noviembre de 1203 y valedor hasta entonces de una moderada política de diálogo en la cuestión albigense, Pedro II de Aragón se convirtió en Las Navas de Tolosa en un campeón de la Cristiandad dotado de un prestigio y autoridad difíciles de igualar. Ello le animó a tomar la iniciativa en el conflicto del Languedoc, donde las conquistas del ambicioso Montfort, apoyado indirectamente por la monarquía de los Capeto, amenazaban ya muy seriamente los poderosos intereses de la Corona de Aragón en la zona $^{71}$.

A principios de 1213, tras la Asamblea y promulgación de los Estatutos de Pamiérs (noviembre de 1212), Inocencio III abogó por hacer treguas con el monarca. La censura papal de la avidez de los cruzados y la orden a Montfort de devolver las tierras conquistadas a los vasallos del rey de Aragón perseguían este objetivo. Pedro II retomó entonces el papel de mediador entre los condes de Tolosa, Foix y Comminges y el clero católico dirigido por Arnaldo Amalarico, quien convocó a los obispos y accedió a negociar con el conderey. Con la profesora Foreville, "podría pensarse que la cruzada común contra los moros de España debió aproximar a los hombres y devolver la concordia a los espíritus", puesto que "la gran preocupación del papa es, ahora, la organización de una nueva cruzada de Tierra Santa". El papa deseaba "poner fin a la guerra albigense a fin de volver las fuerzas vivas de la Cristiandad sobre Jerusalén. ¿El ejemplo de la expedición de España -se pregunta Foreville- no es un estímulo en esta dirección?"72.

Avalado por su victoria sobre los almohades, Pedro el Católico acudió al Concilio de Lavaur (18 de enero de 1213) y pidió el restablecimiento de los derechos perdidos por los nobles meridionales desde el inicio de la Cruzada. Arnaldo, enfermo, no asistió al concilio, pero, asumiendo con radicalidad la defensa de la ortodoxia, respondió duramente, rechazó la petición y exigió al monarca el perdón y una satisfacción a la Iglesia. Pedro II decidió entonces proteger con sus tropas las villas abandonadas a Satán —según Vaux-deCernay - de Tolosa y Montauban, amenazadas por los cruzados. Arnaldo

\footnotetext{
70 MANSILLA, $n^{\circ} 491,522-523$.

7 VENTURA, 193 y sS.

72 FOREVILLE, 132 y $142-143$.
} 
respondió así al conde-rey: vos habéis decidido...defenderlas contra el ejército de Cristo y de la Iglesia. Si estas noticias son ciertas (lo que no complace a Dios) lo son a expensas no sólo de la salvación de vuestra alma, sino incluso de vuestra dignidad real, de vuestra gloria y de vuestro prestigio... ${ }^{73}$.

En este ambiente de tensión, los prelados presionaron de nuevo al pontífice: el conde de Tolosa...el cómplice y el defensor de los herejes...infringe a la Iglesia de Dios todo el mal que puede hacerle sea en persona, sea por sus hijos, sea por sus cómplices, los condes de Foix y de Comminges y Gastón de Bearn, hombres perdidos de vicios y perversos. Aunque el dicho campeón de la fe, el muty cristiano conde de Montfort hay a conquistado casi toda su tierra, como enemigos de Dios y de la Iglesia en una santa y justa guerra, conforme a la venganza de Dios y a la censura de la Iglesia, ellos se empeñan en su locura y rehusan humillarse bajo la poderosa mano del Señor. Recientemente, han ido a recurrir al rey de Aragón gracias al cual proyectan sin duda abusar de vuestra clemencia y ultrajar'a la Iglesia... ${ }^{74}$.

La ruptura definitiva se produjo el 21 de mayo de 1213, cuando, informado de la duplicidad de Pedro II -"engañado" por los legados según Fliche-Martin-, Inocencio III revocó sus anteriores órdenes y amenazó con reavivar la Cruzada contra los herejes ${ }^{75}$. En septiembre, el arzobispo de Narbona advirtió a Pedro el Católico y reunió un concilio para negociar la paz con él. Tras un primer éxito de la diplomacia de Pedro II, Arnaldo y sus colegas, intérpretes casi únicos ante Roma de lo que sucedía en Occitania, inclinaron una vez más la balanza pontificia del lado de la guerra santa. ${ }^{76}$. Como venía ocurriendo desde 1208 , Inocencio III volvió a contemplar el problema albigense a través de los ojos de Arnaldo Amalarico, el jefe de un "partido extremista" (A. Luchaire) enemigo mortal del conde de Tolosa y de todos sus aliados. El enfrentamiento directo entre la Cruzada y la Corona de Aragón era ya inevitable.

El 12 de septiembre de 1213 , junto a los muros del castillo de Muret, una previsible victoria de las fuerzas de la Corona de Aragón y sus aliados meridionales al mando del rey catalano-aragonés se convirtió en uno de los desastres militares de mayor trascendencia en la Historia del Occidente medieval. Las tropas de Montfort destrozaron al ejército aliado y mataron al confiado e imprudente Pedro II, dejando a toda la Cristiandad -en palabras del anónimo continuador de la Canción de la Cruzada- rebajada y cubierta de oprobio ${ }^{77}$. Amaldo Amalarico no estuvo presente en la batalla de Muret, punto de infle-

73 P.VAUX-DE-CERNAY, III, viii(387), 15].

74 Ibidem, (392-397), 152-155.

75 FLICHE-MARTIN, 134.

76 FOREVILLE, 132 y 143.

7 Chanson, IJ, xii(I7).

La Personalidad Internacional de los Papas Hispania Sacra 48 (1996) 
xión clave en el desarrollo futuro de la Cruzada Albigense. Infirmitate gravi detentus, Arnaldo no pudo presenciar como el Señor fuerte y poderoso abatía milagrosamente a los enemigos de la fe cristiana junto a los prelados que habían sido convocados por nuestro padre venerable y amado el arzobispo de Narbona, legado de la Sede Apostólica ${ }^{78}$.

Como bien señala Foreville, 1213 fue un año decisivo para Arnaldo Amalarico. Pese a resultados tan exitosos como la transferencia de tierras y obispados a los fieles jefes y prelados cruzados, se produjo entonces la desafección de Inocencio III por la Cruzada Albigense, es decir, el agotamiento final de la política intransigente ejecutada y personalizada por el legado Arnaldo Amalarico. Finalizó entonces una legación permanente que se había prolongado durante casi 10 años: el 17 de enero de 1214 el arzobispo de Narbona era relevado de su cargo por Roberto de Courson y Pedro de Benevento. Se abría ahora una nueva etapa de medidas conservadoras y contemporizadoras marcadas por el papa, pues -en palabras de Foreville- "todo ha de quedar como está" ante la inminencia del próximo concilio general (Letrán IV, 1215), asamblea que examinaría y regularía todas las cuestiones pendientes ${ }^{79}$.

\section{BALANCE DE LA LEGACIÓN}

"Sin disociar nunca el orden temporal del orden espiritual" - dice Foreville-, Amaldo Amalrico ejerció entre 1208 y 1213 la dirección moral, pero también "estratégica", de la Cruzada contra los albigenses ${ }^{80}$. A esta primera etapa de la guerra santa dominada por la violencia y el fanatismo le había correspondido un legado muy acorde con las circunstancias. Duras tenaz, cruel, inflexible, convencido de la justicia y razón de su causa, defensor a ultranza de la ortodoxia y de los intereses de la teocracia romana y enemigo implacable de la herejía, Arnaldo Amalarico protagonizó una legación cuyo balance no podía ser más favorable para Roma: había puesto en pie la Cruzada; la había continuado de triunfo en triunfo pese a los escandalosos excesos y violencias; no había cedido prácticamente en nada --principios, posiciones o tierrasfrente a sus enemigos; había alternado su misión con una exitosa y resonante campaña contra los musulmanes de España; y, aunque ausente, la había concluido con una victoria campal decisiva frente a la coalición de todos sus

78 Foreville, 143, citando a VauX-DE-Cernay; P.VAuX-DE-Cernay, III, ix(482), I84; (469), 180 -obsérvese que se trata de preludio idéntico al de la carta de Arnaldo para Las Navas-.

79 FOREVILLE, 132-133.

RI) Ibidem, 130. 
enemigos meridionales unidos a la Corona de Aragón, la única potencia capaz de frenarla.

Aunque el final "oficial" de la Cruzada Albigense se produjo en el Tratado de Meaux-París (1229), contemplada en perspectiva, el éxito de la gran cruzada predicada por Inocencio III en 1208, es decir, el "principio del fin" de la disidencia religiosa en Occitania, de la autonomía político-cultural del Languedoc frente a la expansiva monarquía Capeta y del proyecto de hegemonía catalano-aragonesa sobre la región, quedó en gran parte sancionado en 1213 gracias a la eficaz labor del "tándem" formado por el conde de Montfort en el campo militar y el legado Arnaldo Amalarico en los aspectos espiritual, político y organizativo.

\section{EL DUCADO DE NARBONA Y EL OCASO DE ARNALDO AMALARICO (1214-1225)}

Perdida su relevante posición al frente de la Cruzada, entre 1214 y 1225 Arnaldo Amalarico se empeñó en mantener un inútil y desacreditador pulso por el ducado de Narbona con su antiguo aliado Simón de Montfort. En este caso, las ambiciones de Arnaldo tenían un carácter puramente temporal, pues si como arzobispo controlaba sólo una parte de la ciudad, el título ducal suponía la soberanía feudal sobre toda la región.

¿Por qué esta fijación de Arnaldo Amalarico por Narbona -primero el arzobispado, luego el ducado-? Roquebert ofrece una explicación posible a partir de un dato no confirmado aparecido en el siglo XVIII: el historiador J.B. Langlois aseguro en su Histoire des croisades contre les Albigeois (1703) que Arnaldo pertenecía al antiguo linaje de los duques de Narbona, afirmación que también recoge J. Finestres. Aunque el dato es dudoso, "podría darnos la clave de las inmensas ambiciones del abad del Císter, preocupado en reconquistar al conde de Tolosa un patrimonio que estimaba, quizá, corresponderle por derecho"81. Este mezquino enfrentamiento de carácter feudal por un "ducado eclesiástico narbonés" no se resolvió hasta los concilios de Narbona (1227) y Tolosa $(1229)^{82}$.

Entretanto, la estrella del antiguo abad del Císter se fue eclipsando poco a poco. Las contrarias decisiones papales en el IV Concilio de Letrán (1215), los continuos y vanos interdictos contra Montfort, el abandono de sus antiguos colaboradores meridionales y la pérdida de su anterior prestigio y protagonismo explican este declive. Los legados Roberto de Courson y Pedro de Bene-

81 FINESTRES, 175-176; ROQUEBERT, I, $177 \mathrm{y} \$ \$$, 216-2 18.

82 CABAU, 167; ForeviLle, 136. 
vento desde 1214, el papa Honorio III desde 1216 y los condes Amaury de Montfort desde 1218 y Raimundo VII de Tolosa desde 1222 tomaron el relevo en el primer plano de los acontecimientos, abriendo una nueva etapa de la Cruzada Albigense en la que el papel del venerable Arnaldo era cada vez más irrelevante.

El 23 de octubre de 1225 Arnaldo Amalarico donó sus escasos bienes a la abadía de Fontfroide en la que se había retirado. Entre estos bienes estaban todos sus libros, uno de sus cofres para uso de la sacristía, su palafrén, dos carretas con sus caballos y un carretero sarraceno, sin duda -señala Forevilleuno de los cautivos traídos de la gran cruzada de Las Navas de Tolosa en la que tan destacadamente había participado. A final de mes, Arnaldo Amalarico murió en esta abadía. Su cuerpo se trasladó hasta el monasterio de Cîteaux, donde fue enterrado ${ }^{83}$.

\section{EL VENERABLE ARNALDO AMALARICO, HOMBRE DE SU TIEMPO}

Arnaldo Amalarico, al que las fuentes católicas siempre llamaron el venerable Arnaldo, fue un hombre de características peculiares: de una tenacidad infatigable frente a las adversidades y a sus enemigos; de una disciplina sólo comprensible en un monje; de concepciones - dice Foreville- propias de un feudal y, al tiempo, de un orator cuya autoridad reviste un carácter plenamente teocrático; de una capacidad de mando tan intransigente y firme como la de los grandes señores de la guerra de su época; de un talento político capaz de perseguir con obstinación e inteligencia un "proyecto de futuro"; y de una devoción y una fe que en sus apologéticos cronistas le asimilan más a un "alma santa" que a un alto prelado meridional del siglo XIII84. Su papel en el desarrollo de la Cruzada Albigense fue sencillamente determinante. Cruzado de corazón, "de alma" igual que su maestro espiritual San Bernardo -según Foreville-, Arnaldo Amalarico es "el que dirige toda la política de la Cruzada. Se mantiene a veces en la sombra, pero nada se hace sin él"15.

Esta misma imagen de autoridad y santidad es la que acompañó al arzobispo de Narbona en su expedición a España a mediados de 1212. Su liderazgo espiritual y militar tuvo reflejo en buena parte de los momentos claves de la gran campaña de Las Navas de Tolosa: en su decisión de acudir a la Cruzada al mando de los que quisieran acompañarle; en el esfuerzo por vincular a Sancho VII de Navarra a la empresa; en la constancia demostrada después de la

83 FOREVILLE, 136; FINESTRES, 183.

84 VICAIRE, 267; FOREVILLE, 130.

RS P.VAUX-DE-CERNAY, Introducción, XVI; FOREVILlE, 130.

La Personalidad Internacional de los Papas Hispania Sacra 48 (1996) 
retirada de gran parte de las tropas ultramontanas; en algunas acciones militares; en el estímulo a los combatientes durante la batalla; en la defensa de los postulados de la Iglesia durante el asedio de Úbeda; en el deseo de proclamar con su detallada carta la gran victoria hispano-cristiana...

Junto a estas virtudes, sin embargo, las fuentes nos permiten penetrar más allá del halo de "venerabilidad" con el que se adornó la figura de Arnaldo Amalarico, sumergiéndole de lleno en la más cruda realidad del Occidente europeo de principios del siglo XIII. Porque en el abad del Císter pueden observarse actitudes de una violencia, crueldad y fanatismo extremos; de un apasionamiento muy lejano del ideal monástico; de una inteligencia sutil y carente de escrúpulos si el objetivo es salvaguardar los intereses de Dios y de la Iglesia; de una certeza ciega en la pureza, veracidad y justicia de la misión a él encomendada; y de una nula capacidad de tolerancia hacia aquellos a los que consideraba enemigos de Dios. "Servidor fanático de la cristiandad", Vicaire duda que pueda reconocerse en Arnaldo Amalarico "lo que llamaríamos un verdadero religioso" 86 .

A este sombrío retrato puede añadirse también el afán vano y más propio de un gran señor eclesiástico que de un monje cisterciense que Arnaldo demostró en la mezquina disputa por el ducado de Narbona. Este empeño, fruto quizá de esa "concupiscencia del poder" que Labal observa en los cistercienses hostiles al catarismo occitano, le llevó al enfrentamiento con su antiguo aliado Simón de Montfort y a poner en peligro parte de lo logrado por la propia Cruzada Albigense ${ }^{87}$.

Estamos, pues, ante lo que H. Maisonneuve denominó "un espíritu lúcido", pero también "cruel e hipócrita", ante un prototipo de hombre de su tiempo hecho a sí mismo en una fulgurante carrera de ascensos y ante un modelo de muchos de los aspectos propios, tanto para bien como para mal, del eclesiástico que vivió desde una posición de poder y privilegio en el Occidente europeo de principios del siglo XIII.

Monje cisterciense, prior, abad, "abad de abades", jefe supremo de la Iglesia contra la herejía cátara, caudillo cruzado contra el enemigo musulmán en las tierras que le vieron nacer, arzobispo de Narbona y gran señor de Occitania, Arnaldo Amalarico es definido por J. Lekay como el más sobresaliente y controvertido de todos los cistercienses que participaron en la Cruzada Albigense, como un intrépido "campeón de la fe", pero también como el típico sureño violento, ambicioso y fanático ${ }^{88}$. Como afirmó la profesora Foreville,

\footnotetext{
86 VICAIRE, 267.

87 LABAL, 138-139.

89 LEKAY, 45-46.
}

La Personalidad Internacional de los Papas Hispania Sacia 48 (1996) 
Arnaldo Amalarico no se adelanta a su tiempo ni trasciende su medio, sino que -he aquí su principal atractivo-- como muchos de sus coetáneos, "los encarna"89.

k9 FOREVILLE, 136. 